\title{
Cricotiroidotomía por punción en paciente politraumatizado
}

\author{
Mangiarotti E. ${ }^{1}$, Ferro S. ${ }^{1}$, Botero R. ${ }^{1}$, Godoy M. ${ }^{1}$, Pineda F. ${ }^{1}$, Salvatori F. ${ }^{1}$, Chávez Neira D. ${ }^{1}$, Martínez A. ${ }^{1}$, Zai- \\ etta N. ${ }^{1}$, Peroni D. ${ }^{1}$ \\ 1 Hospital Magdalena V. Martínez, Pacheco, Argentina.
}

Caso clínico: Paciente de sexo masculino, de 57 años de edad ingresa inestable a la guardia del hospital luego de sufrir un politraumatismo con traumatismo encéfalo craneano. El paciente se encontraba excitado, con fractura mandibular bilateral, sangrado activo en la bucofarínge, múltiples heridas sangrantes superficiales, saturando $68 \%$ aire ambiente, hemodinámicamente inestable. Ante la necesidad inminente de asegurar la vía aérea, sospecha de fractura de base de cráneo e imposibilidad de utilizar dispositivos video asistidos, se decide realizar una cricotiroidotomía de urgencia asistida con vara de Eschmann. Se realizó premedicación con 100 mg de ketamina endovenosa, se identificó la membrana cricotiroidea, se aplicó anestésico local y, con un bisturí número 11 se realizó una punción horizontal y consiguiente re direccionamiento vertical para la colocación de la vara de Eschmann y posterior pasaje de un tubo endotraqueal número seis asegurando la adecuada oxigenación y ventilación del paciente. Inmediatamente después, el equipo quirúrgico comenzó realizar la traqueotomía de urgencia. El ecofast extendido no diagnosticó sangrado activo torácico ni intraabdominal. Luego de estabilizar hemodinámicamente al paciente y curar las heridas, fue derivado a centro de mayor complejidad.

Discusión: La situación no puedo ventilar/no puedo intubar es infrecuente pero muy temida por los anestesiólogos. En éste caso la técnica de cricotiroidotomía guiada con vara de Eschmann fue utilizada satisfactoriamente en un caso de intubación imposible, por profesionales que anteriormente únicamente habían practicado la maniobra con fantomas. La técnica de punción de la membrana cricotiroidea puede realizarse de distintas formas. Es de nuestro interés resaltar que esta herramienta fácilmente disponible en cualquier guardia hospitalaria fue la que nos brindó el tiempo necesario para la realización de la traqueostomía de urgencia, exámenes complementarios y estabilización hemodinámica del paciente.

https://doi.org/10.25237/congresoclasa2019.105 